\title{
A discussion of building automation and stakeholder engagement for the readiness of energy flexible buildings
}

\author{
Zheng $\mathrm{Ma}^{*}$ (D) and Bo Nørregaard Jørgensen
}

\author{
* Correspondence: \\ zma@mmmi.sdu.dk \\ Center for Energy Informatics, \\ Mærsk Mc-Kinney Møller Institute, \\ University of Southern Denmark, \\ Campusvej 55, 5230 Odense M, \\ Denmark
}

\begin{abstract}
Building automation enables the possibility of energy flexibility in buildings. To investigate the motivation and barriers for the energy flexibility in buildings, this study develops a conceptual framework of the readiness for energy flexible buildings by conducting interviews with building automation suppliers, electricity supplier, district heating supplier, distribution system operator, energy service companies, experts in energy and buildings, building managers, and occupants. The two main parts of the framework are building preparation, grid and market conditions following the impacts of regulation and policies, stakeholder collaboration and integrated building automation. A case study of campus buildings is conducted to demonstrate the framework. The result of the case study shows that the main barriers for buildings to provide energy flexibility are 1) many buildings are too old and need to be refurbished, 2) the benefit of providing energy flexibility to the grid is not sufficient, 3) building management systems need to be either installed or upgraded to response to the demand from the grid. Building managers believe that buildings can provide energy flexibility by building automation and distributed energy resources, but they consider energy efficiency to be more important than providing flexibility to the grid. Meanwhile, occupants have different opinions regarding the comfort level of indoor air quality and control, and the differences are based on various factors, e.g. location, room type, and building ages.
\end{abstract}

\section{Background}

'The energy flexibility of a building is the ability to manage its energy demand and generation according to local climate conditions, user needs and grid requirements' (Jensen et al. 2017a). A large part of the energy use of buildings may be shifted in time, and significantly contribute to increasing flexibility in the energy system (Jensen et al. 2017b). Buildings can provide flexibility to the energy system in various ways, e.g. load shifting and HVAC (heating, ventilation, and air conditioning) control, and participate in two types of DR (demand response) programs: explicit and implicit demand response. Implicit DR assumes that electricity consumers may alter their electricity consumption due to a price signal that is provided at a different time (Mandatova and Lorenz 2013). Meanwhile, explicit DR is divided into traditional-based (e.g. direct load control, interruptible pricing) and market-based (e.g. emergency demand response programs and ancillary services) (Sebastian and Margaret 2016).

(c) The Author(s). 2018 Open Access This article is distributed under the terms of the Creative Commons Attribution 4.0 International License (http://creativecommons.org/licenses/by/4.0/), which permits unrestricted use, distribution, and reproduction in any medium provided you give appropriate credit to the original author(s) and the source, provide a link to the Creative Commons license, and indicate if changes were made. 
To participate in the DR market by providing energy flexibility, buildings are required to comply with the requirements of DR programs. However, the majority of the current building automation systems do not support ADR or building-to-grid functions, due to the immature DR market or the cost of equipment upgrading. Meanwhile, electricity consumers are reluctant to participate in DR programs, because their business routines might be influenced by frequent energy control.

The success of demand response is related to various factors, e.g. regulation, consumers' motivation, electricity suppliers' support (energinet.dk 2011), and collaboration among various stakeholders, e.g. building owners, occupants, and BMS (building management system) providers, etc. The existing literature mainly focuses on one or few stakeholders for energy flexible buildings, e.g. occupants (Dong et al. 2018) or the technical aspects, e.g. VPPs (virtual power plants) (Clausen et al. 2016). The overall picture of stakeholders' involvement and perception of energy flexible buildings is missing (Ma et al. 2017).

Therefore, this paper aims to investigate the opportunities and barriers for buildings to participate in the demand response programs with two aspects: building automation and stakeholders' engagement. Denmark is selected in this paper because there is big potential for energy flexibility in Denmark since it is a political ambition and about $40 \%$ of the energy used in Denmark is buildings. Although it is a general challenge for buildings to provide energy flexibility to the grid due to the lack of readiness or interest, there is higher potential for commercial buildings (e.g. office buildings) compared to other types of buildings (households and industries) because most of the commercial buildings are equipped with building automation (Billanes et al. 2017). Therefore, this paper conducts a conceptual framework of the readiness for energy flexible buildings with a systematic analysis of 18 interviews and along with a case study of campus buildings to demonstrate this framework.

\section{Methodology}

To address shortfalls highlighted above, this paper adopts the qualitative methodology of interviewing to examine and report the experience acquired by various stakeholders involved in the case, specifically their reflection on energy flexible buildings from their own perspectives. Qualitative research methodology is popularly adopted when investigating new fields of study or ascertaining prominent issues (Corbin and Strauss 2008). Interviewing with 18 interviews (shown in Table 1) in this paper provides an in-depth knowledge of the relations of energy flexibility in buildings, building automation, and stakeholders' participation.

Table 1 Interviewees and organizations

\begin{tabular}{ll}
\hline Interviewees & Organizations \\
\hline $2 \times$ Building managers & Energy service, University of Southern Denmark \\
$2 \times$ BMS providers & Schneider Electric \\
& Siemens \\
$1 \times$ Electricity supplier & Energifyn \\
$1 \times$ Energy consultancy & Grøn Energi \\
$1 \times$ Expert in construction and buildings & Civil and Architectural Engineering, University of Southern \\
& Denmark \\
$1 \times$ Expert in building automation and energy & Center for Energy Informatics, University of Southern Denmark \\
$10 \times$ Students & University of Southern Denmark \\
\hline
\end{tabular}


The 18 interviews are conducted as semi-structured face-to-face interviews. The length of each interview with companies, building managers and experts is around $1 \mathrm{~h}$, and 20-30 min for each student interviewee (the interviewed students are the occupants of the campus buildings).

The data analysis in this paper applies the grounded theory (Corbin and Strauss 1990) with a CAQDAS (computer-assisted qualitative data analysis software)- Nvivo for the systematically organizing and analyzing the comprehensive collected data. NVivo helps researchers manage and organize data, and facilitates the analysis of data, identification of themes, gleaning insight and developing conclusions (Sotiriadou et al. 2014).

The researchers firstly open code the interviewed data into Nvivo and then axial code the data into different themes, and the result of the selected coding is presented in the following section.

\section{Result and discussion}

The interviewed results (shown in Fig. 1) show that the readiness for energy flexible buildings is mainly divided into three aspects: buildings, grid \& market, and communication between buildings and grid (Building-to-Grid). Meanwhile, the technical readiness, regulation \& policies, and stakeholder collaboration are important and influence the progress of buildings to provide energy flexibility to the grid.

\section{Building automation and energy flexibility}

All interviewees state that building automation is essential for buildings to be ready and provide energy flexibility. Building automation is able to shift energy demand or shedding energy load without compromising the comfort in buildings. However, the currently installed BMS (building management systems) have a low level of automation due to buildings owners' financial concerns. For instance, there is a discussion about applying B2G (building-to-grid) at the new university super hospital in Odense in Denmark, but it is not certain, because universities as public sector have to make a public tender on new buildings which often result in the cheapest BMS solution, with a low degree of advanced automation.

Building control providers do not see much potentials for themselves to profit from B2G, because B2G is about incentivizing changes in buildings' energy behavior, and this

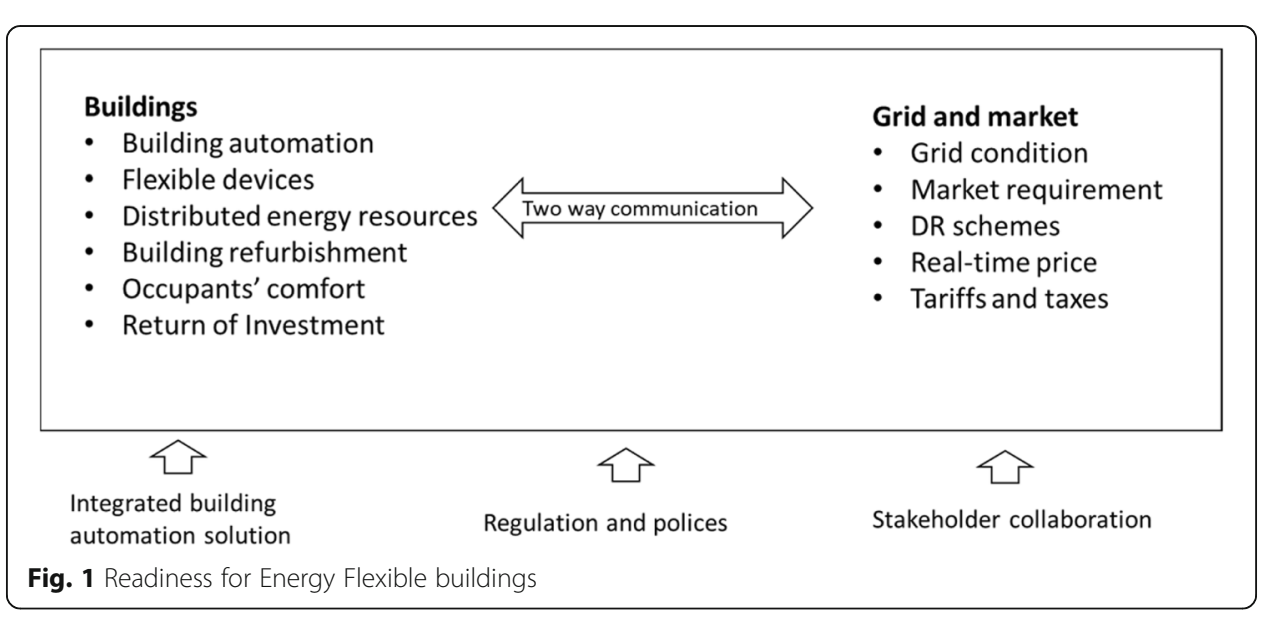


is difficult. Buildings would have to make relatively large changes to their energy behavior for a small economic gain. "If it is easy, it can be done," a BMS provider said and specified that it has to be easy for end users that means automation. It would likely fail if a project relies on end-users to make changes to their daily routine.

Providers of BMS foresee the future of the renewable energy resources, e.g. photovoltaic and electric vehicles. They believe the best solution is not building charging stations but implementing them with the BMS. It would then be necessary to upgrade current BMS that do not provide this function.

To regulate the system with different flexible appliances and electricity generation units, building automation system should include HVAC, electric cars, battery storage, heat pump and/or PVs (photovoltaics), and predict energy consumption of a building based on weather forecasts and occupant behavior.

\section{Concerns from buildings' side}

There are three main concerns for buildings to provide energy flexibility (shown in Fig. 2): how much does it cost compared to the benefit, how much it can influence the comfort, and how complicated it is to integrate into the existing building management system?

One significant barrier that held back building owners from implementing B2G is the investment- it is considered to be too large and the benefit to be too small. Especially, it is too expensive to install a system that fulfills the grid's requirements for flexibility.

- Building control and internal stakeholders' involvement

In theory, for building automation, building managers could remove the controllability from occupants, and simply enforce changes - such as lighting control or temperature control. However, this would lead to dissatisfaction, so it is unlikely for building managers to consider changing occupants' energy behavior. Especially, without sufficient incentives, it does not make sense for consumers to change comfort and behavior.

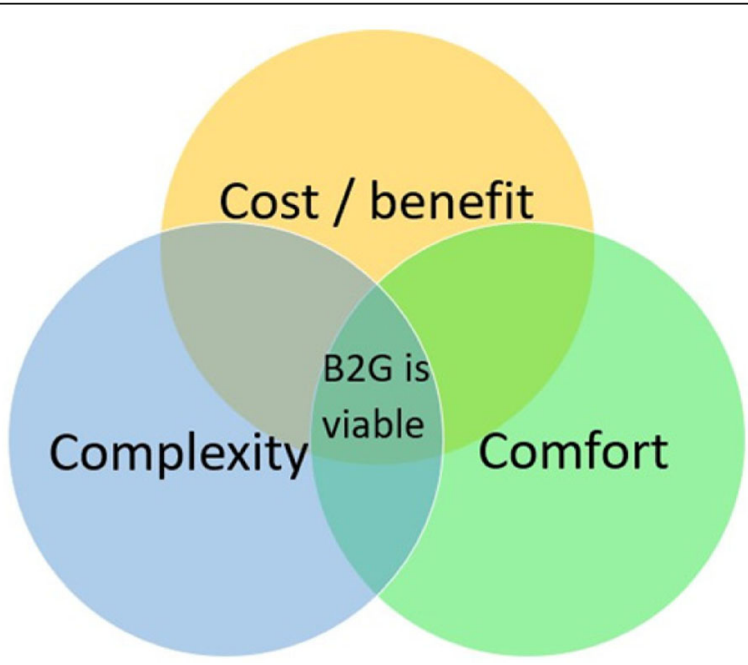

Fig. 2 Three main concerns for buildings to provide energy flexibility 
Usually, various parties are involved in the building control and energy programs, and they all have different agendas. This can make the system more versatile, but it can also make it inefficient since it must comply with different agendas. According to an interviewed building management system provider, the BMS can be customized based on buildings' needs. However, if the system is not used as intended, it might not regulate the energy system in the way that it is designed to do. To the best of our knowledge, this issue has not been addressed by any literature. Most flexible energy systems are still in their trial phases, and developers use the technology as intended. This result shows that company policies affect the implementation of flexible energy technology, and the efficiency of different technologies can vary depending on whether they are used as intended or not.

- Building automation and flexible devices

There are more significant incentives for buildings equipped with building automation to participate in the demand response programs, that buildings can be automated on a large scale with small enough effort. In the future, due to the expected increase in the number of building automation systems, it could become easier for buildings to provide energy flexibility without compromising the comfort or much effort.

Literature shows that it expects consumers would change their behavior when using energy consumed appliances or devices (Hadis Pourasghar and Javidi 2013; Paetz et al. 2012). However, the interviewed electricity supplier believes that consumers most likely stick to their habits and do things at the time which is most convenient for them. This causes the system to be more dependent on devices which can be turned on and off without disturbing the primary service (Hadis Pourasghar and Javidi 2013). Therefore, energy flexibility might not depend on consumer behavior, but more on flexible devices which can regulate their energy consumption automatically. It would be smart that the installation comes with intelligent design, for example, a heat pump which could have flexibility built in by design.

- Building refurbishment

Building refurbishment supports opportunities to reduce energy consumption in buildings. One important factor in building energy refurbishment is the insulation of the building envelope. According to one of the interviewees, a Danish case studyTraneparken shows the decrease in energy consumption after building energy refurbishment. The insulation can be added either from the inside of the building or from the outside. It is easier to insulate from the inside, but this means that some of the indoor space is lost as the walls are getting thicker. Insulation from outside usually is more expensive and buildings grow in size without adding any indoor space.

One problem for buildings, especially private households is that there is no desire for energy refurbishment if building owners cannot see what come out of their investment. In the public opinion, people would rather buy a new kitchen than better insulation.

Referring to the efficiency of new and better insulation in buildings that are already well insulated, an interviewed expert points out that there is no meaning to optimize the energy efficiency by adding insulation with low benefit compared to its cost. 
IAQ (indoor air quality) is decreased as the insulation efficiency is increased (Steinemann et al. 2017). The natural ventilation is lowered as insulation efficiency is increased because the building is more airtight. But in principle, the ventilation efficiency should increase as well when the insulation efficiency is increased, and it should be considered as a ventilation problem, not an insulation problem. The interviewed expert in construction and buildings states that the ventilation optimization is done automatically with systems such as WindowMaster, which automates natural ventilation by mechanically opening and closing windows.

\section{Regulation and policies}

The complexity of the energy system regulation makes the energy system very difficult to be more flexible. It needs to be changed for flexibility to occur, but the needs are very small as the security of the power supply is so high. The interviewees believe that Danish legislation needs to be changed to further promote the implementation of flexible energy systems.

The requirement for providing energy flexibility to the grid is high and complicated. Compared to the rewards, the investment cost to install a system that matches the requirements is considered to be too high. Meanwhile, it would motivate smaller consumers to provide energy flexibility if the regulations and legislation can be easier to fulfill. Nowadays, to participate in the electricity regulating market in Denmark, the requirement is a minimum electricity supply of $10 \mathrm{MW}$, which is much higher than an individual building can provide.

Politics have an influence on the Danish energy system and where solutions and incentives come from. Whenever a large change is needed on the demand or production side of the system, politics are the initiator or the executioner for creating incentives for using new technologies or exclude older technologies.

For instance, large data centers are going to be built in Denmark, Facebook in Odense, Apple in Viborg, Google in Fredericia, and have already created incentives to reduce or remove the levies tied to the use of heat pumps, entirely. With a deal made with the Facebook data center, Fjernvarme Fyn in Odense, Denmark will be able to receive the excess heat and avoid the investment cost for replacing an old district heating plant. This means that there are no levies tied to the heat production and electricity used in household heat pumps. It shows that special rules can apply if a larger change would happen to the system with socio-economically benefit.

Therefore, politics are the decision makers for creating incentives for buildings to become either energy self-sufficient, an integrated part of the grid or both. According to the interview with the energy consulting, levies are the deciding factor for buildings to provide energy flexibility with the socio-economic impact.

\section{Tariffs and taxes}

One large barrier to energy flexibility is the tariffs and taxes associated with power production. For instance, one interviewee introduced that Modkraft3 conducted an experiment to offer consumers free electricity at nights. However, the problem is that the consumers still need to pay the tariffs, which in fact are the main part of the original cost. Therefore, the cost is not significantly reduced. As tariffs cannot be reduced, the 
incentive for behavior change is minimal. In Denmark, PSO is going to be removed during the period of 2017-2022, and the removal of PSO can increase the renewable energy resources and also be expected to encourage more electricity consumption due to the cheaper electricity price without the PSO.

\section{Market condition and microgrids}

According to the interviewees, for the preparation of a future smart and flexible energy system, smart meters with two-way communication and hourly electricity pricing must be implemented to create an incitement for building owners to regulate their energy consumption. By doing so, the peaks in the system can be shifted by using demand response management (DRM). The energy system can be optimized using flexible devices and therefore become more stable.

The Danish government is performing the preliminary work by smart meter installation. According to section 2 of the Danish Act on Smart Meters and Metering of Electricity at the End User (Energistyrensen 2013), all end-users must have smart meters by December 31,2020 . This is the first step towards hourly pricing, but a final step is still needed. New legislation may push the system in a certain direction, but often companies and their policies determine the technologies.

A greater incentive for energy flexibility would be the establishment and operation of microgrids, especially countries without strong and stable grids. Denmark is a small country with a strong grid, and the need for energy flexibility is, therefore, less urgent. Denmark is currently on two separate tracks when it comes to supporting the increased integration of renewable energy. On one hand, new interconnections are made to trade electricity internationally, and on the other hand, the potential for increasing the amount of flexibility is being investigated.

There are two sides to introducing more self-sufficient buildings. For a system response, the increasing number of islanded systems connected to the main grid would result in more peak plants, which would not be a reliable solution. Another downside to the island mode of larger buildings is that the district heating network loses a customer that increases the heat costs for the rest of the network's customers.

Another important question is what the energy flexibility in buildings is supposed to accomplish: is it everyday flexibility or in case of emergency. It could become much cheaper to utilize flexible consumption instead of having large production facilities on standby in case of emergency. In the near future, data centers are being built in Denmark, which will not use flexible consumption and therefore becomes a baseload. This will likely create an incentive for energy flexibility in buildings.

\section{Distributed energy resources}

PVs as a popular distributed energy resource is part of the energy flexible system. However, the current Danish legislation impedes the system. Under the current Danish legislation, PVs are allowed to be used in the distribution system, and PV owners do not need to pay for the electricity transport. The PV owners only need to pay for the net exchange power, independent from the wholesale spot prices or the capacity used in the distribution system. The purpose of this arrangement is to promote PV installations, but it has some unforeseen side effects. The capacity used by the PV owners 
must be paid by other electricity users, which makes it profitable for PV owners, but expensive for everyone else.

There is a potential for electric cars and battery storage in the grid because it can withhold a large amount of energy, e.g. storing surplus electricity production or charging electric vehicles. If energy storage becomes more efficient, it could be more feasible for buildings to be more energy flexible.

\section{Stakeholders' collaboration}

Communication between energy suppliers and consumers is important. For instance, electricity suppliers communicate with their consumers by smart metering, and electricity suppliers believe that providing hourly electricity price and consumption information can create opportunities for consumers to provide energy flexibility to the grid.

Energy suppliers try to communication with buildings regarding incentives for energy efficiency. For instance, a district heating company and an energy consulting company collaborate to analyze energy information and provide the analytical reports to their partners and customers. By this way, all their members have the possibility to explore new opportunities created by incentives.

Collaboration between different actors on the market is important for the joint goals of the energy flexibility to become a reality. One interviewee states that there are several experiments conducted in Denmark already, e.g. Bornholm Sygehus, Modkraft, and Rosengårdscenter.

\section{Case study- SDU campus buildings}

The campus buildings selected in this case study include different types of buildings (e.g. different ages, with different building control systems) and provide different functions (e.g. classrooms, offices, laboratories, etc.) at SDU's campus in Odense. Based on the interview with energy managers and occupants (students), there are five aspects mainly discussed:

\section{Building control systems}

There are four different control systems in the campus buildings regulating different aspects of the energy systems. It increases the complexity of the operations, especially since there is no communication across different systems. This is because campus buildings are publicly financed and must announce all system purchase in public tender. This often leads to a diverse mix of systems that cannot be integrated and centrally controlled.

\section{- Ventilation control}

In the selected case, there is central ventilation controlling multiple rooms in the campus buildings, and it decides whether the ventilation in a room should be opened based on the time schedule for room use. Some larger rooms, such as the auditorium, equips their own individual ventilation system. Ventilation systems are bundled around 10 rooms, each room has a physical valve, that opens and closes depending on the $\mathrm{CO} 2$ measurement in the individual rooms. The $\mathrm{CO} 2$ level is an indicator of the number of people in the room and determines the ventilation operations. Air-conditioning 
is not used in the campus buildings, and the ventilation in most rooms is only regulated based on temperature.

There are sensors that measure the air quality with the respect to the $\mathrm{CO} 2$ level. For instance, "the air quality is considered low when the CO2 level is above 1000 ppm" stated by the interviewed energy manager. It is necessary to check the IAQ in buildings, especially the IAQ problem in newer buildings with the increasing insulation in buildings (Burroughs and Hansen 2011). The ventilation system in newer buildings is adjusted to keep the CO2 level below 1000 ppm. However, the ventilation system in the older buildings cannot be varied and always ventilates rooms by assuming the maximum amount of people in the room. This makes the ventilation less energy efficient. There are no mechanical ventilation systems in the very old campus buildings, they are only ventilated using natural ventilation.

In general, the difference between manual and automated ventilation is that manual ventilation either ventilates too much or too little, and there is an optimal amount of ventilation and energy consumption optimized by automated ventilation (Zhou and Haghighat 2009).

\section{- Temperature control}

There is automatic temperature control in the campus buildings (e.g. public areas, classrooms, hallways, etc.). Radiators on campus are fitted with a motor, which control the temperature centrally. "A timer decides that from 8 am to $4 \mathrm{pm}$, the temperature is $21^{\circ} \mathrm{C}$, and in the remaining time, the temperature is lowered to about $19^{\circ} \mathrm{C}$. There is a central control system of temperature in the newer buildings. A setpoint temperature for the whole building can be manually controlled in different classrooms at $\pm 2{ }^{\circ} \mathrm{C}$ from the standard temperature. However, automatic control systems based on existing thermal management in public buildings are not very energy efficient ( $\mathrm{Li}$ et al. 2012). Some rooms (e.g. offices/small rooms) are regulated by occupants directly via thermostats.

\section{- Lighting control}

Lighting is usually controlled by movement sensors that turn off light when rooms are not in use (Guo et al. 2010). Almost everywhere on campus needs to manually turn on light. The light level in newer buildings is controlled and regulated automatically based on indoor light sensors.

In general, classroom management in campus buildings is good but not yet optimal. This may be due to the vastness of campus buildings and the differences in construction designs and ages. Compared to older buildings, newer buildings have more control measures installed to improve or maintain conditions and facilitate space management. This would explain the report of poor ventilation in older buildings and is further supported by the presence of standard protocols to respond to these reports of poor indoor conditions.

- Plans for energy control system improvement

The interviewed experts and energy managers believe that the implementation of building management systems can optimize buildings' energy efficiency, "the goal is to 
control as much as possible, heat, ventilation, and light, based on the needs of occupants" stated by the interviewed energy manager.

The current indoor climate regulation is handled through set-point regulation with limited manual input. The energy team aims to increase the automation of the regulation by incorporating predictive control mechanisms and would like to track inhabitants to minimize unnecessary regulation. This change in regulation scheme and control technology must be undertaken while managing a large network of relationships that should be satisfied.

For the improvement of heating and temperature, the main concern is to not heat too much when there are no people in the rooms. Therefore, many different sensors and systems are incorporated to make sure this does not happen. If the system can better communicate, the temperature could possibly be lowered. More regulation according to use patterns can help, e.g. linking the booking system to temperature control. For instance, in a newer building, the temperature is increased a few hours before a room is occupied, and the temperature is lower for the rest of the time. If it can be implemented and optimized in all rooms, temperatures could be lowered when rooms are not used, resulting in energy savings.

The main concern for ventilation is IAQ when rooms are not in use or only few people are in a room. It is especially essential for older buildings. The energy team expects to have better documentation of building energy data in general in the future, especially for buildings that do not have sensors at the moment.

The current control schemes are linear control and have no prediction of occupant behavior. The energy team intents to change this regulation scheme to be more predictive. This can be accomplished by using machine learning to predict occupant behavior and take weather data into account when lighting, ventilation, and temperature must be regulated. The current regulation relies partly on direct user input, and the new scheme would rely on indirect user input via occupant tracking and more accurate $\mathrm{CO} 2$ concentration measurements to determine how to regulate. In this context, the definition of a satisfactory comfort level becomes increasingly important.

\section{Energy management and activities}

The energy management of the campus buildings includes a variety of activities. In general, the energy management activities are divided into: $2 / 3$ of time for consumption data collection, coordination with related, energy database maintenance, and 1/3 time on finding areas where improvements are possible. There are approximately $100 \mathrm{em}$ ployees working for a variety of tasks with energy savings. For instance:

- Energy meter control, collection, and registration of water, electricity, and heat consumption

- Screening energy solutions for optimization and energy savings potential (ventilation, lighting, motors, toilets, faucets, etc.)

- Responsible for energy spending

- Responsible for temperature and air quality regulation

- Maintaining the energy consumption database

- Analyze photovoltaic cells 
- Supervising contracts, bids and the process of construction

- Reporting to the Danish Energy Agency

\section{Building refurbishment and investment for energy saving}

The potential energy savings are dependent on buildings' age and construction. Therefore, each building needs to be inspected individually to find out the most efficient solution for the building energy refurbishment.

All campus buildings are built after the establishment of building regulation in Denmark. For instance, the best energy efficient building is the building following the building regulation -BR20. According to the current building regulation, some older buildings are not energy efficient and there is potential to save a lot of energy. An analysis of the cost-effectiveness of energy refurbishment of multi-family houses built in the 1970s supports the statement that there is a potential for energy refurbishment of older buildings (Dodoo et al. 2017).

The energy management team for campus buildings only check the technical insulation, such as insulation used for heat transport in pipes or in equipment rooms. Refurbishment might improve insulation can be an extra layer of insulation in the roofs or three-layer windows. In general, large energy refurbishments are only made in the combination of existing refurbishment plan that usually is not related to energy savings. The interviewed energy managers for campus buildings and an expert in building and construction both believe that the insulation in buildings is more important than the connection of buildings to the grid or the energy flexibility in buildings. However, both agree that energy flexibility can become more feasible in the future.

In this case, 10 million DKK for 18 projects has been invested in energy-saving solutions that are supposed to obtain 2 million DKK in energy savings. All projects have different payback periods. For example, photovoltaic installation is worth 4 million DKK, for an annual saving of 700,000-800,000 DKK with a payback period of approximately 6 years. Other smaller projects, such as changing lighting sources and changing freezers with a payback period of 9 years.

\section{Distributed energy resources and energy flexibility}

The distributed energy resources on the campus are PVs with a yearly production of $400,000 \mathrm{kWh}$. Soon a PV system producing additional 600,000 kWh will be installed on the roof of the main campus building. This will further lower dependency on the main grid. The produced electricity is integrated into the campus grid because it would be more complicated to allocate it to a specific area, and it makes no difference due to the large size of the campus grid.

There is a wish to participate in demand response schemes. For instance, it has been considered to use the excess heat from the cooling of server rooms incorporation with heat pumps for the campus district heating demand. However, there are barriers in the form of rigid billing methods and budgetary constraints which limit the possibilities for the participation. Meanwhile, the energy consumption is very fixed based on people's working schedule. Therefore, shifting consumption is not an option. Storage might create opportunity, but the investment might be too high without significant financial benefits. 


\section{Occupants' opinions and involvement}

All interviewed occupants are students and have 3-5 years study experience in the campus buildings. The interview results show that many factors influence the perceived comfort levels and everyone has their own perception on the satisfactory comfort level. Different parameters are prioritized differently from person to person that makes the definition of a comfort level that everyone agrees on very difficult. The interviewed occupants suggest that the university should consider the diversity of comfort level when designing new control schemes. Meanwhile, the levels of comfort are different across locations on the campus due to a lack of consistency in terms of climate conditions. Although the energy manager stated that ventilation is regulated, the interviewed occupants indicated that ventilation is severely lacking in some cases, and some interviewed occupants are not even aware of its existence. The perceived levels of comfort increase as the building ages decrease. In general, the comfort level in the newest buildings is perceived to be the highest, because the newly built buildings focus on the occupants and comfort (Frontczak and Wargocki 2011).

Good air quality is essential for occupants, as bad indoor climate affect occupants' ability to learn and work (Frontczak et al. 2012). The interviewed occupants stated that "In general, the air quality is good in larger areas, but bad in smaller rooms", "The classrooms quickly become very bad and sweaty" and "(...) the group rooms make you crazy". One of the interviewees also pointed out: "There is no air from outside the rooms and very bad ventilation". Smaller rooms, such as group rooms and classrooms are not well ventilated, and the air quality affects the students' work and concentration. There is more complaint regarding air quality in closed rooms in the campus buildings, as stated by the interviewed occupants "Toilets in particular - a mix of urine and bad ventilation".

The general opinion towards thermal comfort on campus is 'too cold at most locations', as two interviewed occupants stated that "It is always too cold all-around campus", and "I always have to wear a thick shirt". When asking whether the cold condition affects students' work, the answer from both is "Yes, very much. It shifts my focus away from lectures". However, the two interviewed occupants were both female and gender can affect the feeling of temperature, that literature shows that female is more sensitive to indoor temperature than male (Wan et al. 2009). The interview result might be different if the interviewees are male.

The interviewed occupants have different opinions about lighting. For instance, one interviewed occupants stated that "The lighting is generally good", while another other stated that "Light is very bad on campus. The distribution of lighting is bad, as some places are very dark", even saying that "I cannot see without my glasses". The lighting quality varies by locations, as one interviewed occupant stated "In the OU44 building, the natural light is good, but the manual light control does not work properly", and other interviewed occupant stated "(...) other classrooms such as room U140 has too little natural light". A general suggestion by the interviewed occupants is more natural light in the older parts of the campus buildings because more natural light and vibrant colors can stimulate students and make them feel less lethargic (Mills et al. 2007).

The majority of interviewed occupants have little experience with poor classroom management. However, one interviewed occupant stated that "one classroom that was ridiculously poorly ventilated". The energy manager clarified that "if there are no measurements, the $\mathrm{CO} 2$ levels or temperature may fall above or below standards" and 
manual measurements and evaluation are the standard protocol if poor conditions are reported. The perceived control levels vary across interviewed occupants. In general, interviewed occupants feel that they do not have much control over heating and cooling in the facilities, but have a high degree of control over lighting. Some of them are unaware of any controllable installations that lead to frustration and ultimately impacts on the reputation of certain areas on campus. Interviewed occupants believe that fully automated indoor control might have some undesired consequences, such as unintended temperature drops, and they need to manually control indoor climate when the building automation fails to provide proper indoor climate.

The energy manager stated that there are certain procedures at the service department dealing with reported complaints and feedback. However, interviewed occupants seldom report the complaints to the service department, although some do not satisfy the indoor air quality and control in campus buildings.

\section{Conclusion}

This paper developed a conceptual framework based on interview data of stakeholders' opinions. The framework presents three important parts for the readiness of energy flexible buildings (building automation, building-to-grid, and energy flexibility market) with the impacts of regulation and policies, stakeholder collaboration and integrated building automation.

However, the case study with campus buildings shows that none of the three aspects are ready in the current situation in Denmark. The energy flexibility market is not ready and there is no incentive for buildings to provide energy flexibility. For example, the requirement for participating ancillary service in Denmark is $1 \mathrm{MV}$ that most of the commercial buildings cannot participate in this market directly. Meanwhile, aggregators aggregating consumption side energy flexibility are not allowed to participate in the Danish energy market. There is usually a fixed electricity price for the commercial buildings in Denmark that is based on negotiation with energy suppliers. Although buildings can choose hourly electricity price, the energy bill is not significantly different from the fixed price.

Building managers believe that buildings can provide energy flexibility by building automation and distributed energy resources. However, the main task for buildings is still energy efficiency due to the national and international policies on energy efficiency and monetary benefit from the energy saving. The main barriers for buildings to provide energy flexibility are 1) building refurbishment is needed in many buildings, 2) the monetary benefit of providing energy flexibility to the grid is not significant, 3) building management systems need to be upgraded and respond properly to activities in rooms and demand from the grid.

From the occupants' perspective, indoor comfort is the main concern, mainly due to their concerns about working performance. Occupants have different opinions regarding the comfort level of indoor air quality and control, and the differences are based on various factors, e.g. location, room type, and building ages. Although there are concerns and complaint regarding indoor comfort, the majority of occupants have not compliant with the service department.

The conceptual framework presents the essential elements for the energy flexible building readiness that contributes not only to the field of building-to-grid but the integration from both building and grid sides. Stakeholders play different roles and it is 
necessary to understand and fulfill their barriers and motivations in the business of energy flexible buildings. This paper investigates the main relevant stakeholders to provide a big picture from their own perspectives. The case study shows the current building energy management and activities with related stakeholders' inputs that demonstrates the gaps between the reality and the future of the energy flexible buildings.

Action research with simulation is recommended in the future research to demonstrate the transition of current buildings to become energy flexible buildings. The influential factors that affect related stakeholders and their business should be further investigated to develop and validate solutions for energy flexibility in buildings.

\section{Abbreviations}

ADR: Automated demand response; B2G: Building-to-grid; BMS: Building management systems; CAQDAS: Computerassisted qualitative data analysis software; DR: Demand response; HVAC: Heating, ventilation, and air conditioning; IAQ: Indoor air quality; PVs: Photovoltaics; VPPs: Virtual power plants

\section{Acknowledgments}

This study was conducted as part of EBC Annex 67 Energy Flexible Buildings. The data collection was conducted by the Energy Technology Master students in the course of 'Scientific Methods' at the University of Southern Denmark in Autumn 2017

\section{Funding}

This paper is completed under no funding.

\section{Availability of data and materials}

Data sharing not applicable to this article as no datasets were generated or analyzed during the current study.

\section{Authors' contributions}

ZM carried out the first draft of the paper and BNJ participated the paper revision. Both authors read and approved the final manuscript.

Ethics approval and consent to participate

Not applicable

Consent for publication

Not applicable

\section{Competing interests}

The authors declare that they have no competing interests.

\section{Publisher's Note}

Springer Nature remains neutral with regard to jurisdictional claims in published maps and institutional affiliations.

Received: 20 August 2018 Accepted: 10 October 2018

Published online: 25 October 2018

\section{References}

Billanes JD, Ma Z, Jørgensen BN (2017) Consumer central energy flexibility in office buildings. J Energy Power Eng 2017(11): $621-630$

Burroughs HE, Hansen SJ (2011) Managing Indoor Air Quality. The Fairmont Press, Inc., Lilburn

Clausen A, Umair A, Ma Z, Jørgensen BN (2016) Demand Response Integration Through Agent-Based Coordination of Consumers in Virtual Power Plants. Springer International Publishing, Cham, pp 313-322

Corbin J., Strauss A., (2008) Basics of Qualitative Research: Techniques and Procedures for Developing Grounded Theory, 3 Thousand Oaks: Sage Publications.

Corbin JM, Strauss A (1990) Grounded theory research: Procedures, canons, and evaluative criteria. Qual Sociol 13(1):3-21

Dodoo A, Gustavsson L, Tettey UYA (2017) Final energy savings and cost-effectiveness of deep energy renovation of a multistory residential building. Energy 135:563-576, 2017/09/15

Dong B et al (2018) Sensing and data acquisition. In: Wagner A, O'Brien W, Dong B (eds) Exploring occupant behavior in buildings: Methods and Challenges. Springer International Publishing, Cham, pp 77-105

energinet.dk, Smart grid in Denmark 2.0 - Implementation of three key recommendations form the Smart Grid Network, 2011

Energistyrensen (2013) Bekendtgørelse om fjernaflæste elmålere og måling af elektricitet i slutforbruget. Available: https:// www.retsinformation.dk/forms/r0710.aspx?id=160434

Frontczak M, Wargocki P (2011) Literature survey on how different factors influence human comfort in indoor environments. Build Environ 46(4):922-937, 2011/04/01

Frontczak M, Schiavon S, Goins J, Arens E, Zhang H, Wargocki P (2012) Quantitative relationships between occupant satisfaction and satisfaction aspects of indoor environmental quality and building design. Indoor Air 22(2):119-131 
Guo X, Tiller D, Henze G, Waters C (2010) The performance of occupancy-based lighting control systems: a review. Lighting Res Technol 42(4):415-431

Hadis Pourasghar K, Javidi MH (2013) An efficient home energy management system for automated residential demand response. In: 2013 13th international conference on environment and electrical engineering (EEEIC), pp 307-312

Jensen SØ et al (2017a) Energy flexibility as a key asset in a smart building future. In: Annex 67: energy flexible Buildings http://annex67.org/media/1470/position-paper-energy-flexibility-as-a-key-asset-i-a-smart-building-future.pdf

Jensen S $\varnothing$ et al (2017b) IEA EBC annex 67 energy flexible buildings. Energ Buildings 155:25-34, 2017/11/15

Li F, Wang YC, Zhou L (2012) An automatic control method for central heating of public buildings. Appl Mech Mater 3249: 241-244

Ma Z, Dalmacio Billanes J, Kjærgaard MB, Jørgensen BN (2017) Energy flexibility in retail buildings: From a business ecosystem perspective, 2017 14th International Conference on the European Energy Market (EEM), Dresden, pp. 1-6. https://doi.org/ 10.1109/EEM.2017.7981962

Mandatova P., Lorenz G. (2013) EURELECTRIC paper. Network tariff structure for a smart energy system.

Mills PR, Tomkins SC, Schlangen LJ (2007) The effect of high correlated colour temperature office lighting on employee wellbeing and work performance. J Circadian Rhythms 5(1):2

Paetz A-G, Dütschke E, Fichtner W (2012) Smart Homes as a Means to Sustainable Energy Consumption: A Study of Consumer Perceptions. J Consum Policy 35(1):23-41

Sebastian S, Margaret V (2016) Application of demand response programs for residential loads to minimize energy cost. In: 2016 international conference on circuit, power and computing technologies (ICCPCT), pp 1-4

Sotiriadou P, Brouwers J, Le T-A (2014) Choosing a qualitative data analysis tool: a comparison of NVivo and Leximancer. Ann Leisure Res 17(2):218-234, 2014/04/03

Steinemann A, Wargocki P, Rismanchi B (2017) Ten questions concerning green buildings and indoor air quality. Build Environ 112:351-358, 2017/02/01

Wan JW, Yang K, Zhang WJ, Zhang JL (2009) A new method of determination of indoor temperature and relative humidity with consideration of human thermal comfort. Build Environ 44(2):411-417, 2009/02/01

Zhou L, Haghighat F (2009) Optimization of ventilation system design and operation in office environment, part I: methodology. Build Environ 44(4):651-656, 2009/04/01

\section{Submit your manuscript to a SpringerOpen ${ }^{\circ}$ journal and benefit from:}

- Convenient online submission

- Rigorous peer review

- Open access: articles freely available online

High visibility within the field

- Retaining the copyright to your article

Submit your next manuscript at $\boldsymbol{\nabla}$ springeropen.com 